\title{
Acoustic detection of the spatial and temporal distribution of fish shoals in the Bay of Biscay
}

\author{
Carla Scalabrin ${ }^{(1)}$ and Jacques Massé \\ (1) IFREMER, Centre de Brest, Laboratoire Technologie Pêche, DITI/GO, B.P. 70, 29280 Plonzané, France. \\ (2) IFREMER, Centre de Nantes, Laboraloire d'Écologie halieutique, DRV/RH, B.P. 1049, 44037 Nanles cedex 01, France.
}

Received December 9, 1992; accepted March 10, 1993.

Scalabrin C., J. Massé. Aquat. Living Resour., 1993, 6, 269-283.

\begin{abstract}
Echo sounder data were used to investigate the spatio-temporal variability of shoal behaviour in the Bay of Biscay. Data collected from annual surveys were processed using MOVIES-B software in order to measure this variability. The software was designed to measure morphological, energetic and space-time distribution descriptors from the acoustic signal received from fish shoals. Two surveys, DAAG 90 and DAAG 91, provided the appropriate characteristics for such an analysis. The survey's objective was to obtain relative abundance indices for the anchovy (Engraulis encrasicolus) biomass in the Bay of Biscay. The surveys were carried out in the same area (southern Bay of Biscay), at the same period (April) within one year interval (1990 and 1991), using the same equipment (vessel, acoustic system, fishing gear) in a multispecies environment. Frequency distributions for every descriptor were obtained and used to describe the acoustic detection of fish shoals. The analysis of frequency distributions of space-time descriptors (year, day-hour and bottom depth) allowed the construction of derived discrete variables, which defined new subsets of detections. The subsets were then described by the continuous variables. A principal components analysis was used to describe the multidimensional data structure and to describe behaviour patterns. The size and external outline unevenness are correlated groups of shoal descriptors, but are independent of the water column shoal position and the degree of internal shoal structure. An important feature is shoal size variability between years. Significant differences in shoal characteristics were found between bathymetric zones of the same region and the pattern was similar between years. This spatial wariability is related to the distribution of different species between bathymetric zones. Although it was not possible to explain size variability between years, this will be necessary to improve shoal characterization. More knowledge about oceanographic conditions, the productivity level and availability of food, predator pressure and accurate identification of shoal species is required, in order to study the spatial or temporal variability in size and behaviour of shoals.
\end{abstract}

Keywords: fish shoal, fisheries acoustics, Bay of Biscay, pelagic fish.

Détection acoustique de la distribution spatio-temporelle des bancs de poissons observés dans le golfe de Gascogne.

Résumé

Des données acoustiques ont été utilisées pour étudier la variabilité spatio-temporelle du comportement des bancs de poissons dans le golfe de Gascogne. Pour mesurer cette variabilité, les données collectées pendant deux campagnes annuelles ont été traitées à l'aide du logiciel MOVIES-B. Ce logiciel est capable de calculer des descripteurs morphologiques, énergétiques et de distribution spatio-temporelle des signaux acoustiques retro-diffusés par les bancs de poissons. Les deux campagnes, DAAG 90 et DAAG 91, présentent des caractéristiques appropriées pour ce type d'analyse. Leur objectif était d'obtenir des indices relatifs d'abondance pour la biomasse de l'anchois (Engraulis encrasicolus) dans le golfe de Gascogne. Le travail de prospection a été réalisé dans la même zone (sud du golfe de Gascogne), pendant la même période de l'année (avril) avec un an d'intervalle (1990 et 1991), en utilisant le même équipement (navire, système acoustique et engin de pêche) dans un environnement multispécifique. Les distributions de fréquence 
de chaque descripteur ont servi pour la description des détections acoustiques des bancs de poissons. L'analyse des distributions de fréquence des descripteurs spatio-temporels (année, heure de la journéc et sonde) a permis la construction des variables discrètes qui définissent des nouveaux sous-ensembles de détections. Les sous-ensembles sont décrits par les variables continues. Une analyse en composantes principales, réalisée sur les données, a permis de décrire la structure multidimensionnelle sous-jacente et de dégager des modèles de comportement. Les descripteurs de taille ct les descripteurs de l'irrégularité du contour des détections de bancs sont positivement corrélés entre cux, mais non-corrélés avec la position du banc dans la colonne d'eau, ni avec le degré de structure interne du banc. Une importante variabilité de la taille des bancs de poissons a été observée entre les deux années. Les détections acoustiques des bancs sont sensiblement différentes parmi les trois zones bathymétriques dans la même région, caractéristique qui se maintient d'une année sur l'autre. La variabilité spatiale est liée à la distribution des espèces en fonction de la bathymétrie. Malgré l'impossibilité d'expliquer la variabilité de la taille des bancs entre ces deux campagnes, identifier les causes de cette variabilité sera nécessaire pour amćliorer la qualité de la caractérisation des bancs de poissons. Pour étudier la variabilité spatiale ou temporelle de la taille ct du comportement des bancs de poissons, une meilleure connaissance des conditions océanographiques, du niveau de productivité et de la disponibilité de nourriture, de la pression des prédatcurs et une complète identification de l'espèce de poissons qui forment le banc serait nécessaire.

Mots-clés : banc de poissons, acoustique halieutique, variabilité, golfe de Gascogne, poisson pélagique.

\section{INTRODUCTION}

Shoals may be studied in the laboratory, or as wild aggregations in the marine environment. Laboratory research provides experiments under controlled conditions, where a great number of parameters are known with accuracy and the experiment can be repeated. Results from laboratory research are very important to understand and quantify shoaling behaviour and to analyse the dynamics of the shoal structure (Whitney, 1969; van Olst and Hunter, 1970; Shaw, 1978; Pitcher and Partridge, 1979; Partridge, 1981). However, comparison between data obtained from enclosed aggregations and data from wild aggregations should only be indicative, since shoaling behaviour may be affected by different constraints and quantifying methods may not be the same.

Wild shoals are usually studied using acoustic techniques, but underwater photography (Graves, 1977; Buerkle, 1987) and aerial measurements (Squire, 1978; Hampton et al., 1979; Hara, 1985) have also been used.

There are two acoustic techniques to investigate wild shoals: vertical echo-sounders and lateral sonars. However, only a partial description of the real shape, size and behaviour of wild shoals is obtained. The limitations are a function of the equipment and its resolution. Vertical echo-sounders measure the height and length of a shoal passing under the vessel. This provides good vertical resolution but less accurate horizontal measure. Sonars measure crosswise (width) and lengthwise dimensions, but the beam angle distortion may also introduce a bias in measurements. In order to compute the shoal volume using only two dimensions, assumptions must be made about the third dimension or it is necessary to combine the two techniques (Misund, 1991).

At present, few acoustic data have been published about size, shape and behaviour of wild shoals (Smith, 1970; Mais, 1974; Elminowicz, 1975; Squire, 1978;
Hampton et al., 1979; Hara, 1985; Misund et al., 1992; Misund and Aglen, 1992; Appenzeller and Leggett, 1992). Generalization from this research is difficult because of the different acoustic techniques and conspicuous species dependent shoaling behaviour. The limited data available from the same circumstances makes the analyse of spatial-time variability difficult. An exception to the last point, is the study of Mais (1974) covering a long period of systematic pelagic surveys in the California current. He showed that shoal size and variability in shoaling behaviour is greater among seasons than among regions.

The purpose of the present paper is: (1) to describe wild shoal size, shape and behaviour from vertical echo-sounder observations, (2) to describe and compare shoal detections among different bathymetric zones in order to assess spatial variability, (3) to describe and compare shoal detections in relation to day-time in order to verify different shoaling behaviour and (4) to compare detection sets between annual surveys, carried out in the same region, in order to assess yearly-temporal variability.

The software, MOVIES-B (Weill et al., 1993) associated to the acoustic data acquisition and processing system INES/MOVIES, was designed to perform shoal by shoal echo-integration. The shoal characteristics were quantified automatically from the acoustic signal.

\section{METHODS}

\section{Survey area description}

Two surveys, DAAG 1990 and DAAG 1991, were carried out, one year apart, in order to assess an abundance index of anchovy (Engraulis encrasicolus) in the Bay of Biscay. Data from these surveys were considered as appropriate input to study spatial and 
temporal variability, since the surveys were realized in the same area (southern Bay of Biscay), in a multispecies environment, at the same period (April) and with the same equipment (vessel, acoustic system, fishing gear).

A zone located between $44^{\circ}$ and $45^{\circ} \mathrm{N}$ was selected because it provided:

- a good agreement in the location of the transects (similar geographic positions) between the two years;

- similar ESDU numbers (Elementary Sampling Distance Unit of one nautical mile). 194 and 218 nautical miles for April 1990 and 1991, respectively;

- high density of fish for both years with the same observed species: sardine (Sardina pilchardus), anchovy (Engraulis encrasicolus), horse mackerel (Trachurus trachurus) and mackerel (Scomber scombrus).

For both surveys, this zone was sampled by six isobath perpendicular transects, from 25 to 200 meters bottom depth, with a spacing of ten nautical miles.

Additional information was provided by 12 identification hauls in 1990 and 9 in 1991. A midwater trawl with large size mesh $(16 \mathrm{~m})$ in the fore part and a vertical opening of $22 \mathrm{~m}$ was used in both surveys.

Catch composition by trawl were applied to the echo-integration data results in order to compute specific relative abundance indices for each year in three different strata. Biomass calculation and species target strength values used in this analysis are those described by Diner and Le Men (1983). The three strata were selected by depth criteria.

The biomass estimates for both years were similar: 497 for 1990 and 436 for 1991 . The results presented in table 1 are expressed in percent of the total biomass index for the whole area. The abundance index of mackerel (Scomber scombrus) may be overestimated because of target strength uncertainty and insufficient trawl results that should be applied to the high deviations observed in that area.

The changes in species distribution from the coast to continental shelf break were similar for both years. Sardine was found nearshore, anchovy in the intermediate zone (between 50 and $100 \mathrm{~m}$ depth), mackerel and horse mackerel offshore (fig. 2). There were small differences, in 1991 the distribution pattern showed a lower density of fish nearshore and a distribution of sardine extending farther offshore.

\section{Data analysis}

Data was collected at sea using the INES-MOVIES system, connected to a $38 \mathrm{kHz}$ narrow-band echosounder with TVG amplification of $20 \log$ R. A pulse duration of $1 \mathrm{~ms}$ and an echo-integration threshold of $12 \mathrm{mV}$ applied during the acquisition process. The digital sampling frequency of the detected echo was equal to $7.5 \mathrm{kHz}$ which enables a $0.10 \mathrm{~m}$ vertical resolution. To recognize an echo set as a shoal, the MOVIES-B parameters were held constant during all analyse (number of pings $\geqslant 3$; number of samples above integration threshold $\geqslant 48$; total energy $\geqslant 0$ ).

The data set was limited to only day-time (7 AM to $9 \mathrm{PM}$ ) and survey speed (mean vessel speed of 9 knots). Shoals detected during trawling activity were not included in the analysis. The data matrix was composed of 7325 shoals and 32 descriptors (tables 2 and 3 ). The number of shoals in both surveys is quite similar. There were 3735 shoals in 1990 and 3590 shoals in the 1991 survey. No species' identification was assigned to shoals, since these were only survey data.

Height, length, cross sectional area and perimeter are variables measuring the size of a shoal. Circularity and unevenness describe the degree of smoothness in shoal outline. High values for these descriptors mean that the shoal has a very uneven outline, a large perimeter

Table 1. - Biomass abundance indices by depth strata and species, computed from pelagic trawl catches compositions, $(+)$ : presence, but not significant value.

\begin{tabular}{|c|c|c|c|c|c|}
\hline \multirow{2}{*}{ Survey } & \multirow{2}{*}{ Species } & \multicolumn{3}{|c|}{ Depth strata } & \multirow{2}{*}{ Total area } \\
\hline & & $<58 \mathrm{~m}$ & $58 \mathrm{~m}<d s<102 \mathrm{~m}$ & $>102 \mathrm{~m}$ & \\
\hline \multirow{4}{*}{$D A A G 90$} & Sardina pilchardus & 3.9 & 4.1 & + & 8.1 \\
\hline & Trachurus sp. & 0.5 & 0.4 & 2.5 & 3.5 \\
\hline & Scomber sp. & 1.3 & 0.7 & 74.8 & 76.9 \\
\hline & various & 0.3 & + & + & 0.1 \\
\hline \multirow{5}{*}{$D A A G 91$} & Sardina pilchardus & 0.6 & 4.0 & 13.5 & 18.0 \\
\hline & Engraulis encrasicolus & 0.6 & 4.8 & + & 5.5 \\
\hline & Trachurus sp. & + & 0.9 & 4.5 & 5.4 \\
\hline & Scomber sp. & + & 4.2 & 64.3 & 68.6 \\
\hline & various & 1.1 & 1.1 & 0.4 & 2.5 \\
\hline
\end{tabular}



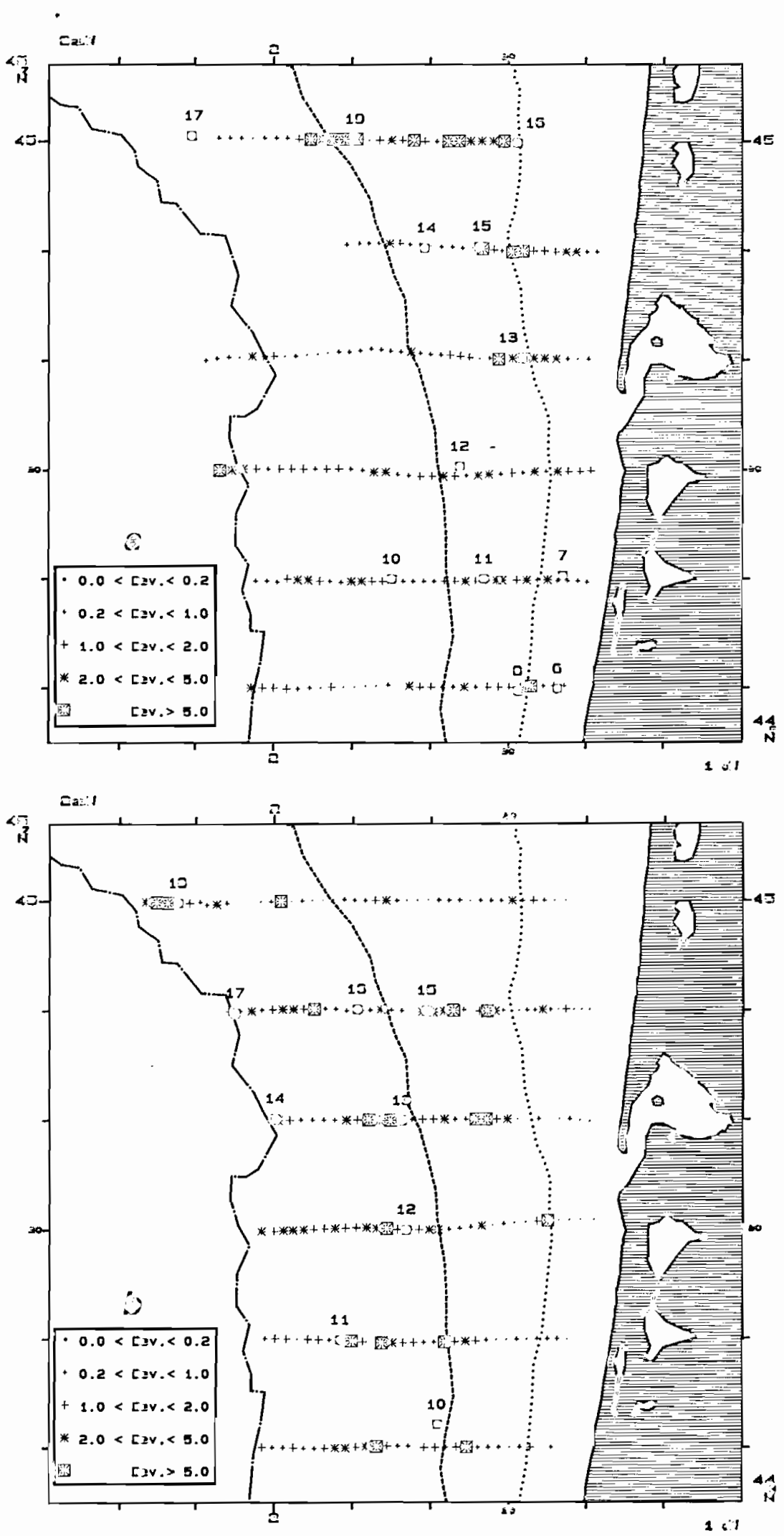

Figare 1. - Abundance of fish detections computed from registered deviations per nautical mile and pelagic haul positions, a: $D A A C ;$ 1990, b: DAAG 1991 surveys. 
Tatle 2. - Summary of descriptors computed for each shoal by INES-MOVIES system.

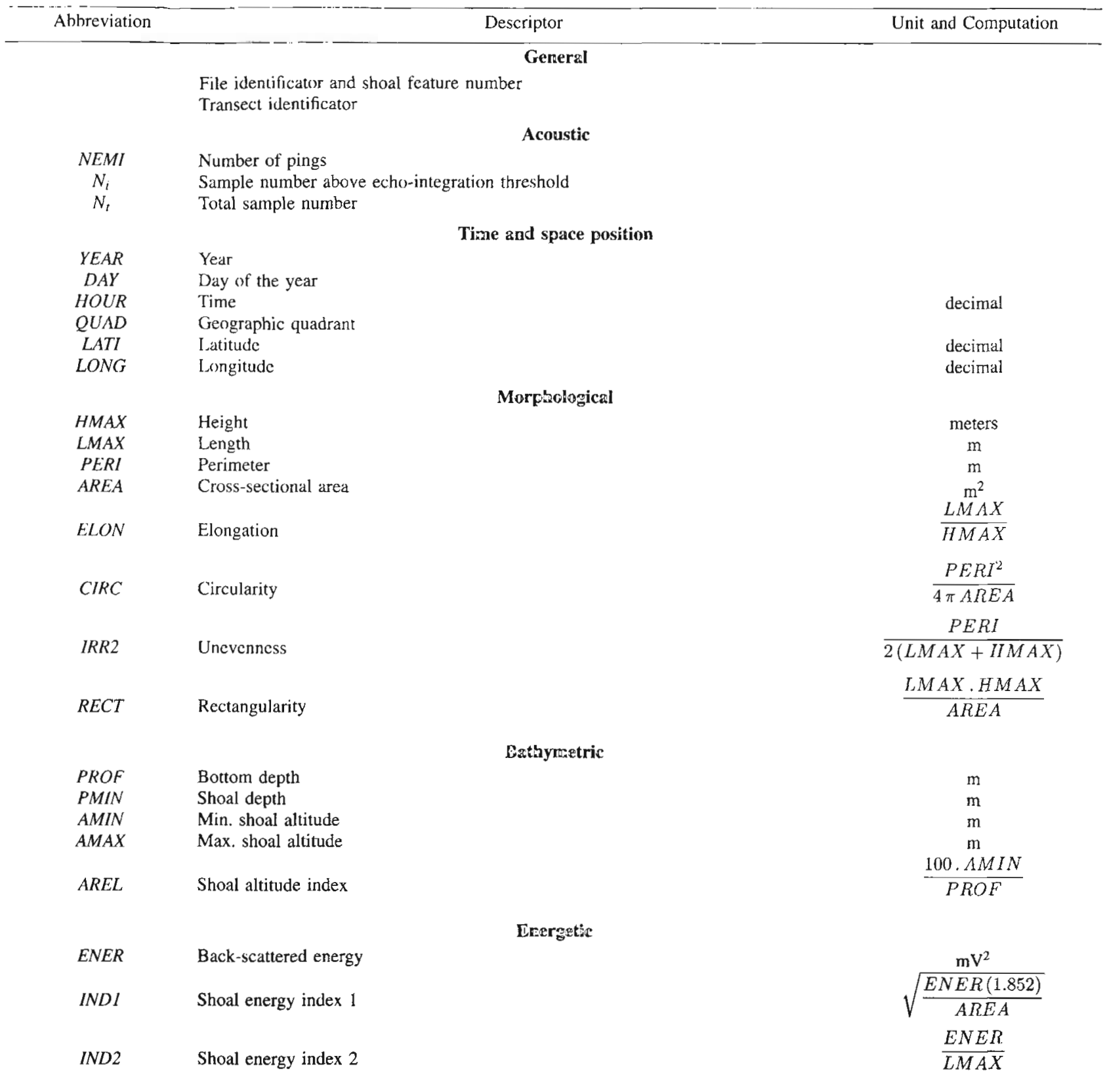

in relation to the cross sectional area. Elongation describes the shoal shape. A value of 1 represents a circular shape, whereas values greater than 1 indicate an elliptical shape. Bathymetric descriptors indicate the absolute and relative position of the shoal in the water column. A low value of the shoal altitude index means that the shoal is close to the bottom.

Shoal back-scattered energy is related to acoustic characteristics of the species and to the internal stucture of the shoal. Shoals presenting high packing density values should have high values for the back- scattered energy. In order to neutralize size effects (positive correlation between shoal back-scattered energy and size), the energy value was normalized by the shoal cross sectional area. Shoal energy index 1 descriptor attempts to reveal the internal structure of a vertical shoal detection by quantifying the relationship between energy and cross sectional area.

No attempt was made to transform these data in a density measure, such as the number of fish per volume, since no assumptions were made about the real volume of the shoals or the species identification. 
Table 3. - Summary of qualitative variables built for the analysis.

\begin{tabular}{|c|c|c|c|c|}
\hline \multirow{3}{*}{ Norminal descriptor } & \multicolumn{3}{|c|}{ Nominal descriptors } & \multirow{3}{*}{ Histogram } \\
\hline & \multirow{2}{*}{ Abrev. } & \multicolumn{2}{|c|}{ Frequency } & \\
\hline & & absolute & relative & \\
\hline \multicolumn{5}{|c|}{ Survey modal classes } \\
\hline DAAG 1990 & DA90 & 3735 & 0.51 & $* * * * * * * * * * * * * * * * * * * * * * * *$ \\
\hline$D A A G 1991$ & DA91 & 3590 & 0.49 & $* * * * * * * * * * * * * * * * * * * * * * * *$ \\
\hline $58-102 \mathrm{~m}$ interm. zone & SON2 & 2991 & 0.41 & $* * * * * * * * * * * * * * * * * * *$ \\
\hline $102-160 \mathrm{~m}$ offshorc & SON3 & 2938 & 0.40 & $* * * * * * * * * * * * * * * * * * *$ \\
\hline \multicolumn{5}{|c|}{ Day time modal classes } \\
\hline $07-11 \mathrm{~h}$ morning & MORN & 1963 & 0.27 & $* * * * * * * * * * * * *$ \\
\hline $11-17 \mathrm{~h}$ afternoon & AFTE & 2690 & 0.37 & $* * * * * * * * * * * * * * * * * *$ \\
\hline DAAG90 offshore & $90 \mathrm{~S} 3$ & 982 & 0.13 & $* * * * * * *$ \\
\hline DAAG91 nearshore & $91 \mathrm{SI}$ & 299 & 0.04 & $* *$ \\
\hline DAAG91 interm. zone & $91 \mathrm{~S} 2$ & 1335 & 0.18 & $* * * * * * * * *$ \\
\hline DAAG91 offshore & $91 \mathrm{~S} 3$ & 1956 & 0.27 & $* * * * * * * * * * * * *$ \\
\hline \multicolumn{5}{|c|}{ Survey $\times$ Day time modal classes } \\
\hline DAAG90 moming & $90 \mathrm{AM}$ & 712 & 0.10 & $* * * * *$ \\
\hline DAAG90 afternoon & $90 \mathrm{PM}$ & 919 & 0.13 & $* * * * * * *$ \\
\hline DAAG90 evening & $90 \mathrm{EV}$ & 2104 & 0.29 & $* * * * * * * * * * * * * * *$ \\
\hline DAAG9l morning & $91 \mathrm{AM}$ & 1251 & 0.17 & $* * * * * * * *$ \\
\hline DAAG91 afternoon & $91 \mathrm{PM}$ & 1771 & 0.24 & $* * * * * * * * * * * *$ \\
\hline DAAG9l evening & $91 \mathrm{EV}$ & 568 & 0.08 & $* * * *$ \\
\hline
\end{tabular}

Nevertheless, high values for this descriptor are indicative of high packing density values and highly structured shoals.

In order to describe and compare detections with different bathymetric positions, a beam-width correction should be applied over size and size dependent descriptors (Johannesson and Losse, 1973). Beam correction is computed as:

$$
B_{c}=2 r \tan \frac{\alpha}{2}
$$

where $r=$ depth of the shoal gravity center and $\alpha=$ beam angle at $3 \mathrm{~dB}$. Adjusted shoal length, $L_{\alpha}$, is simply computed by:

$$
L_{\alpha}=L M A X-\kappa\left(B_{c}\right)
$$

with the decision rule:

$$
\kappa= \begin{cases}0 & \text { if } L M A X<2 B_{c} \\ 1 & \text { if } L M A X \geq 2 B_{c}\end{cases}
$$

If the beam correction is applied over the length of the shoal, $\kappa=1$, then the following corrections are applied over all size dependent descriptors. Adjusted shoal perimeter $\left(P_{\alpha}\right)$ is computed as:

$$
P_{\alpha}=P E R I-2 B_{c}
$$

Cross sectional area correction is less straightforward. Correction is equivalent to the area of an ellipse were the first axis is the half of the beam correction and the second axis is the half of the average shoal height:

$$
A_{c}=A R E A-\frac{\pi \cdot I M O Y \cdot B_{c}}{1}
$$

where HMOY is the average shoal height in meters, computed as the mean sample number per ping normalized by the number of samples per vertical meter, in this case equal to ten:

$$
H M O Y=\frac{N_{t}}{N E M I .10}
$$

The apparent shoal height should also be corrected to take account of the pulse duration and the correction is more important for small shoals. A method is proposed by MacLennan and Simmonds (1992) where the apparent shoal height may be adjusted by removing the half of the pulse duration. Nevertheless, no correction was applied to the height data in this study, since the pulse duration was constant in both surveys and the adjustement may be considered as a systematic error where all the observations are similarly affected.

Other size dependent descriptors (elongation, circularity, rectangularity, unevenness, energy index 1 
Table 4. - Mean, standard deviation (S.D.), and test value ( $t . \mathrm{V}$.) for active descriptors used to perform PCA from global and survey data. Test value is a two-tailed test analogous to "Student's $t$-test", associating mean comparaison between modal classes for each descriptor. The hypothesis of significant differences between modal classes is possible if the value for the test is outside the range $-t_{0.995}$ to $t_{0.995}$ (or -2.58 to 2.58), with a significance level at 0.05 and $\propto$ degrees of freedom. The test value sign indicates the rclative position of the modal class mcan value: above $(+)$ or below $(\rightarrow)$ the general mean value.

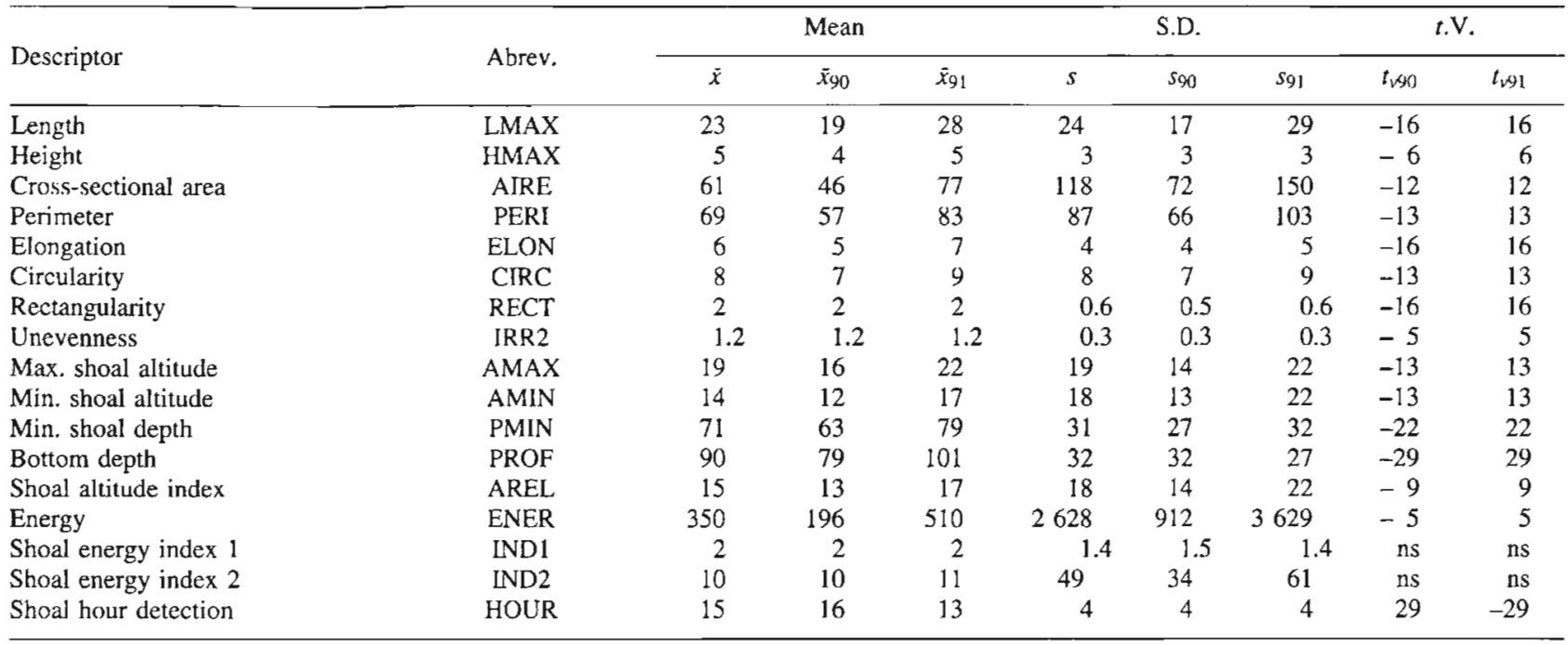

and energy index 2) are computed as indicated in table 2 , but using adjusted values of length, perimeter and cross sectional area.

The beam width adjusted descriptors from the data matrix were submitted to a principal components analysis (PCA) in order to describe the multidimensional data structure. A dimension reduction of the descriptor space (variable selection) was made to assure variable homogeneity. The subset was composed of 7325 shoals and 17 descriptors, among them, 16 were continuous variables but shoal hour detection was considered as a supplementary variable (table 4). The variables were standardized to neutralize the effects of different scaling and no assumptions were made about their distributions.

Frequency distributions of continuous variables were analysed in order to identify those with a multimodal distribution. A multimodal distribution may be characteristic of a heterogeneous population. This analysis provides empirical thresholds to group values in a qualitative variable. The new variable allows the grouping of shoal detections into subsets which may be described or characterized by the values of other variables.

All frequency distributions were unimodal and positively skewed $\left(\beta_{1}>0\right)$, except the shoal bottom depth and shoal hour detection which were selected to define thresholds.

The frequency distribution of bottom depth values from all shoal detection (DAAG 90 and DAAG 91 shoals) is trimodal (fig. 3). It was possible to set thresholds which correspond to relative minimum frequency values. A new qualitative variable was built grouping shoal detections in three modal classes corresponding to nearshore, intermediate and offshore zones (table 3 ).

The shoal hour detection frequency distribution was quadrimodal, but this may be explained by the method of data collection. Relative minimum frequency values correspond to trawling hours and these detections are not included in the data matrix. The thresholds were arbitrarily chosen and the new qualitative variable groups values in three modal classes (table 3): morning, afternoon and evening.

Two other qualitative variables were built crossing survey modal classes versus depth modal classes and survey modal classes versus day hour modal classes (table 3).

All analyse were performed by SPAD.N, a multivariate descriptive statistical software (Lebart et al., 1988).

\section{Principal components analysis}

Principal components analysis may be applied to summarize the information contained in a data matrix $\mathbf{R}$ and simultaneously to provide a clear visual or geometric representation of the information (Lebart et al., 1984). PCA is considered as an ordination metric technique (Laurec, 1979; Legendre et Legendre, 1984) where the objective is to find a subspace with a reduced number of dimensions that provides a good fit for the observations and the variables. In this case, the distances between the points in the subspace provide an accurate representation of the distances in the 


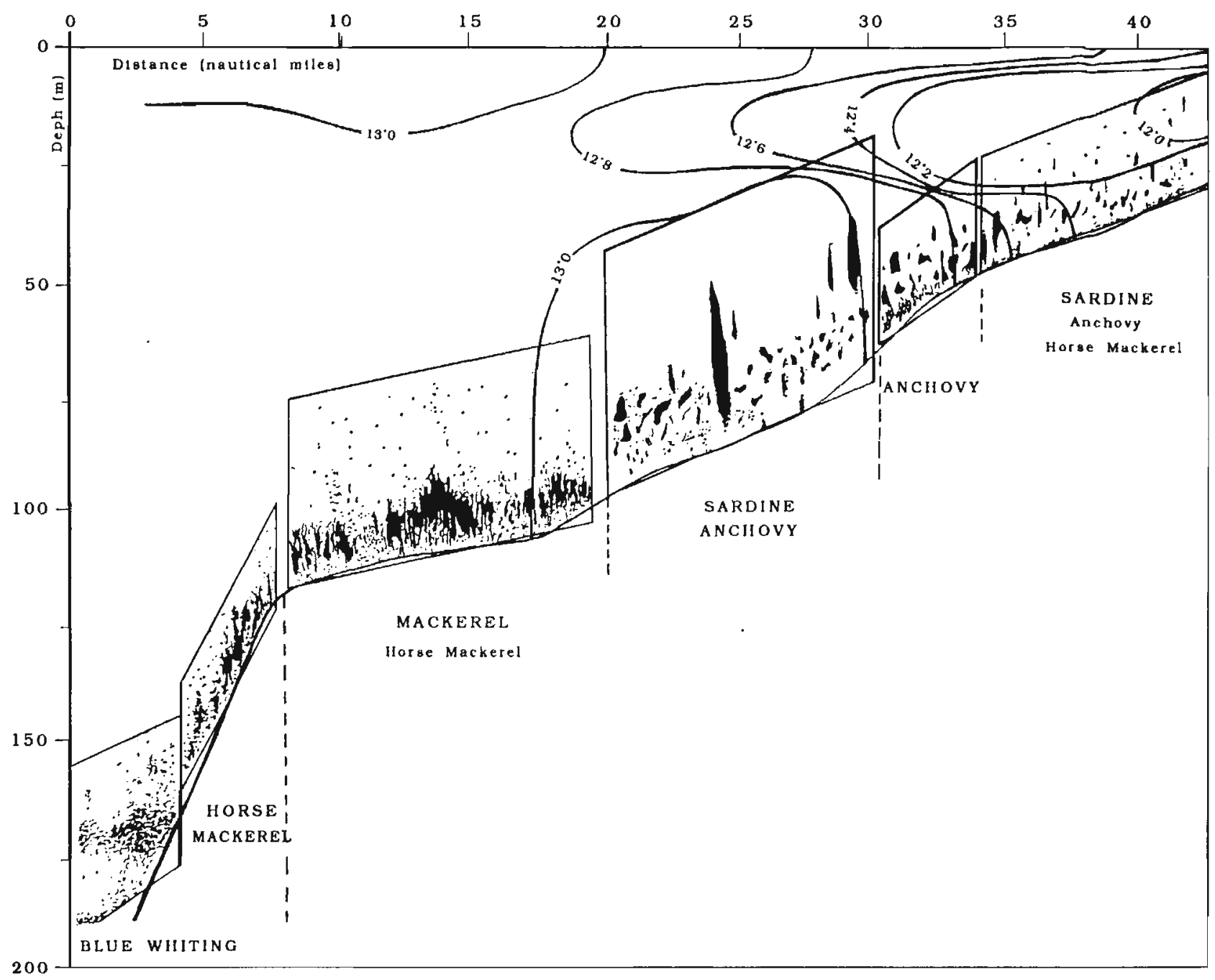

Figure 2. - Typical fish detection and water temperature distribution as observed along a transect during acoustic surveys in the Bay of Biscay.

original data matrix. It may be used as a reduction technique or as a descriptive technique.

The data matrix $\mathbf{R}$ is of the order $(n, p)$, where $n$ are the number of rows (observations) and $p$ the number of columns (variables). One row is a point in the variable space, $R^{p}$, and one column is a point in the observation space, $R^{n}$. Two points-observations that are close in the space $R^{p}$ must have similar values on the $p$ variables. Two points-variables have similar values over the sample of observations if they appear together in the space $R^{n}$. This means that they are measuring almost the same thing.

The analysis was made in $\mathrm{R}$ mode where variables were standardized. This transformation of the raw data allows a fit that accounts in the best possible way for the distances between individual points and gives equal weights to each of the variables in defining the distances among the observations.
The optimal solution is to define the subspace $q$ that provides a good fit for the observations. This is given by finding the set of the orthogonal eigenvectors of the correlation matrix cerresponding to the $q$ largest Eigenvalues, ranked in descending order.

The first Ejgenvector is a one-dimensional vector, a straight line passing through the origin of the set of points, corresponding to the direction of the largest dispersion of points. The second one corresponds to the direction of the largest dispersion of points which is orthogonal to the first Eigenvector. Eigenvectors are called axis or factors by PCA and correspond to a crealed variable which is the linear combination of the initial variables. Each Eigenvector is associated to an eigenvalue, which represents the proportion of total variance that is explained by each factor and is expressed in percentage. The coordinates of the variables-points are the correlation coefficients between variables and factors. 


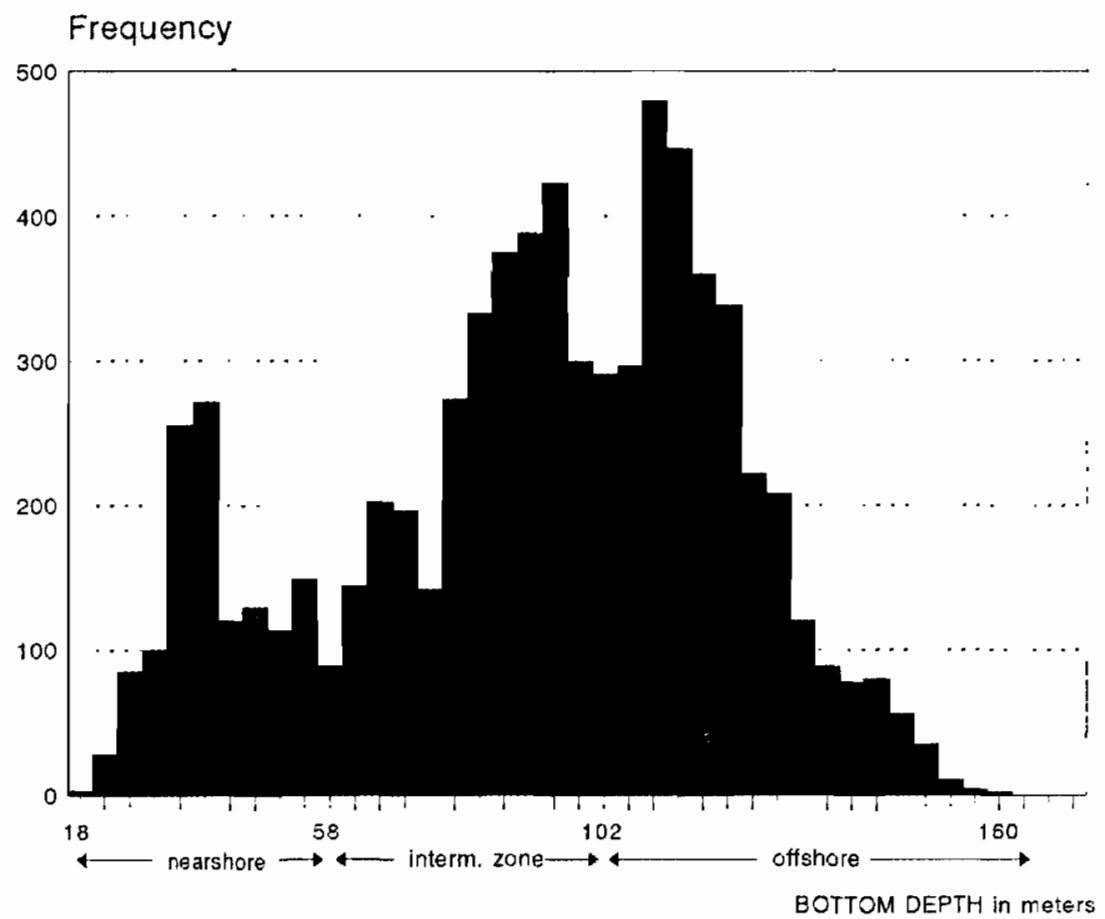

Figure 3. - Frequency distribution of bottom depth values for the whole set of shoal detections $(n=7325)$.

\section{RESULTS}

\section{Analysis in $R^{n}$ space}

Figures $4 a$ and $b$ show the factorial planes I and II for continuous variables.

The first plane is formed by factors 1 and 2 and accounts for $49 \%$ of the variance. Factor 1 represents $29 \%$ of the total variance and is characterized by morphological descriptors. The first factor may be defined as a size factor and the descriptors are strongly correlated. Length, cross sectional area and perimeter are well represented on this plane, with values of $\cos ^{2}>0.7$. Circularity $\left(\cos ^{2}=0.65\right)$ describes the outline smoothness of a shoal detection. Large shoals have an uneven outline and small shoals have a very smooth outline.

Factor 2 characterizes the bathymetric position of the shoals in the water column and accounts for $20 \%$ of the total variance. This is defined as a water column position factor. Descriptors characterizing the second factor are well represented by the first plane with values of $\cos ^{2}>0.9$.

As factors represent orthogonal Eigenvectors, the set of descriptors characterizing each factor are uncorrelated. So, shoal size is not correlated with its position in the water column.

The second plane is formed by the factors 1 and 3. Factor 3 is characterized by energy descriptors and represents $16 \%$ of the total variance. It may be defined as an energy factor describing the shoal structure. Shoal energy index 1 and $2\left(\cos ^{2} \geq 0.7\right)$ are not correlated to the shoal size, or to its position in the water column.

The first three factors account for $64 \%$ of the total variance, but this percentage should not be interpreted as a percentage of information summarized by the factors, since the variance corresponding to the remaining factors may be purely random noise (Lebart et al., 1984).

\section{Analysis in $R^{p}$ space}

It is pointless to present the scattergram of the 7325 shoals. However it is possible to plot the centroids of the various qualitative variables (modal classes) which were constructed.

Figures $4 c$ and $d$ present the survey modal classes (DA90 and DA91), bottom depth modal classes (SON1, SON2 and SON3) and survey modal classes crossed to bottom depth classes (90S1, 90S2, 90S3, 91S1, 91S2 and 91S3) on the factorial planes I and II.

The surveys are different for the first two factors: in 1990 shoals are smaller and closer to the bottom than shoals in 1991. Shoal mean length and mean altitude from the bottom are, respectively, 19 and $12 \mathrm{~m}$ in 1990, 28 and $17 \mathrm{~m}$ in 1991, with meaningful test-values (table 4).

Surveys are slightly different for the third factor, but this difference is less significant.

Bottom depth modal classes (continuous line) may be used to characterize shoals detected in different 

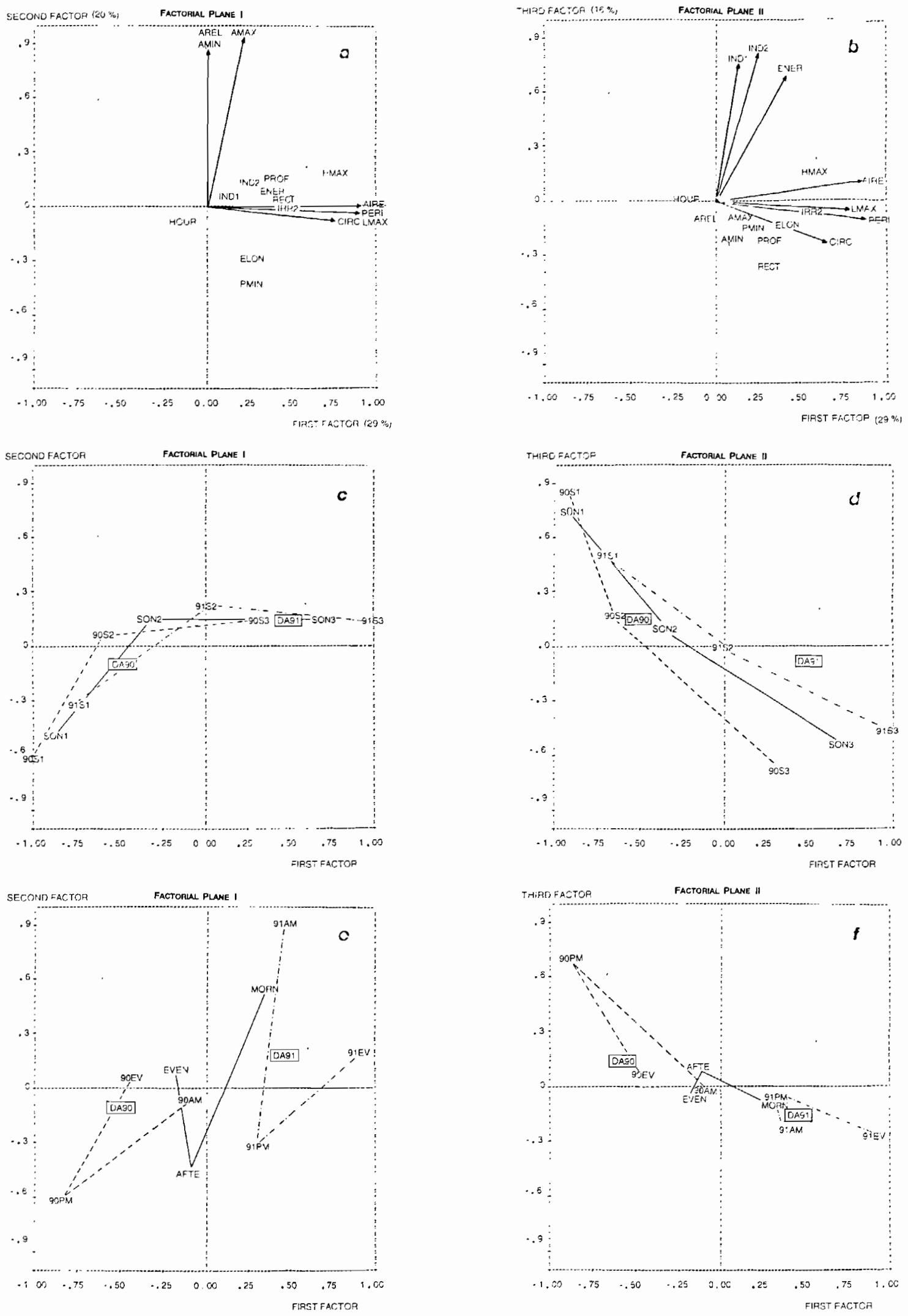

Aquat. Living Resour. 
Figure 4. - Principal components analysis graphic results. (a): factorial plane I with variables projections (correlation circle composed by the first and second factors). (b): factorial plane II with variables projections (correlation circle composed of the first and third factors) (c) and (d): centroids of surveys, bottom depth and cross-modal classes on the factorial planes I and II; 1990 survey=DA90; 1991 survey= DA91; bottom depth modal classes (SON1, SON2 and SON3) joined by a continuous line; cross-modal classes (survey $\times$ bottom depth) $=90 \mathrm{~S} 1,90 \mathrm{~S} 2$ and $90 \mathrm{~S} 3$ joined by $(--), 91 \mathrm{~S} 1,91 \mathrm{~S} 2$ and $91 \mathrm{~S} 3$ joined by (-.--). (e) and (f): centroids of survey, shoal hour detection and cross-modal classes on the factorial planes 1 and II; 1990 surveys = DA90; 1991 survey = DA91; shoal hour detection modal classes (MORN, AFTE and EVEN) joined by a continuous line; cross-modal classes (survey $\times$ shoal hour detection) $=90 \mathrm{AM}, 90 \mathrm{PM}$ and $90 \mathrm{EV}$ joined by (---), 91 AM, 91PM and 91EV joined by (-.---).
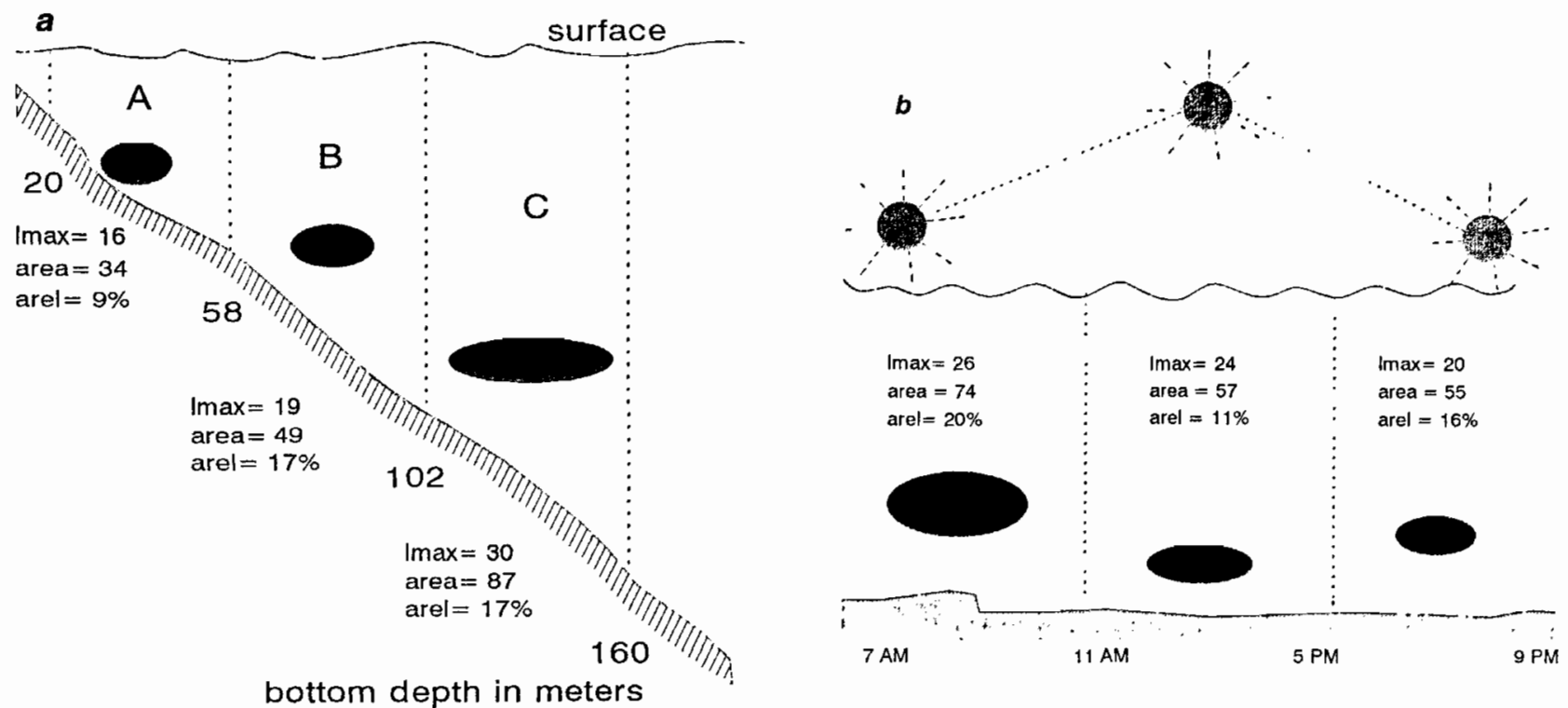

Figure 5. - Schematic representation of shoal size and relative water column position. Size is represented by mean values of length (m) and cross-sectional area, $\mathrm{m}^{2}$. Relative water column position is expressed by mean shoal altitude index values. (a): function of bottom depth modal classes, (b): function of shoal hour detection modal classes.

bathymetric zones of the Bay of Biscay. Nearshore shoals are separated from offshore shoals by the size and the water column position factors. Nearshore shoals are smaller and closer to the bottom than intermediate zone and offshore shoals. Intermediate zone and offshore shoals have the same water column position but they have different coordinates on the size factor, intermediate zone shoals are smaller than offshore shoals (fig. $5 a$ ).

Patterns for cross modal classes (bottom depth $\times$ survey) seems to be similar, but 1991 pattern is shifted right and upward. This means that shoals from 1991 survey are farther from the bottom than 1990 shoals.

The similarity between cross modal classes patterns is indicative of a small variability between years with respect to the three bottom depth groups of detections, at least on the first factorial plane. Variability is greater among groups of detections that are found in each bottom depth modal class, regardless of the year.

With respect to the third factor, plane II, there is a difference between nearshore shoals and offshore shoals, since their distance on the factorial plane is significant. Nearshore shoals have larger values for energy index than offshore shoals. The same pattern is found for cross modal classes (bottom depth $\times$ surveys) which may be indicative of small interannual variability with regard to the energy index factor.

Figures $4 e$ and $f$ shows the centroids of shoal hour detection modal classes (MORN, AFTE and EVEN), joined by continuous line and shoal hour detection modal classes crossed with survey modal classes (90AM, 90PM, 91EV, 91AM, 91 PM and 91EV) joined by dashed lines.

Morning and evening shoals are significantly correlated with the first factor, but morning shoals are larger than evening shoals.

Morning and afternoon shoals are significantly correlated with the second factor but opposed by the origin. Afternoon shoals are thus closer to the bottom than morning shoals (fig. $5 b$ ).

Patterns for cross variables are quite similar, but there is a rightward rotation of the 1991 evening modal class. The positions of the 90-91 patterns are opposed by the first factor, so 1990 hour modal classes have smaller shoals than 1991 hour modal classes.

Significant differences may not be found among shoal hour detection modal classes with respect to the third factor, except for the extreme points: 90PM (afternoon shoals from 1990 survey) and 91EV (evening shoals from 1991 survey). Afternoon shoals 


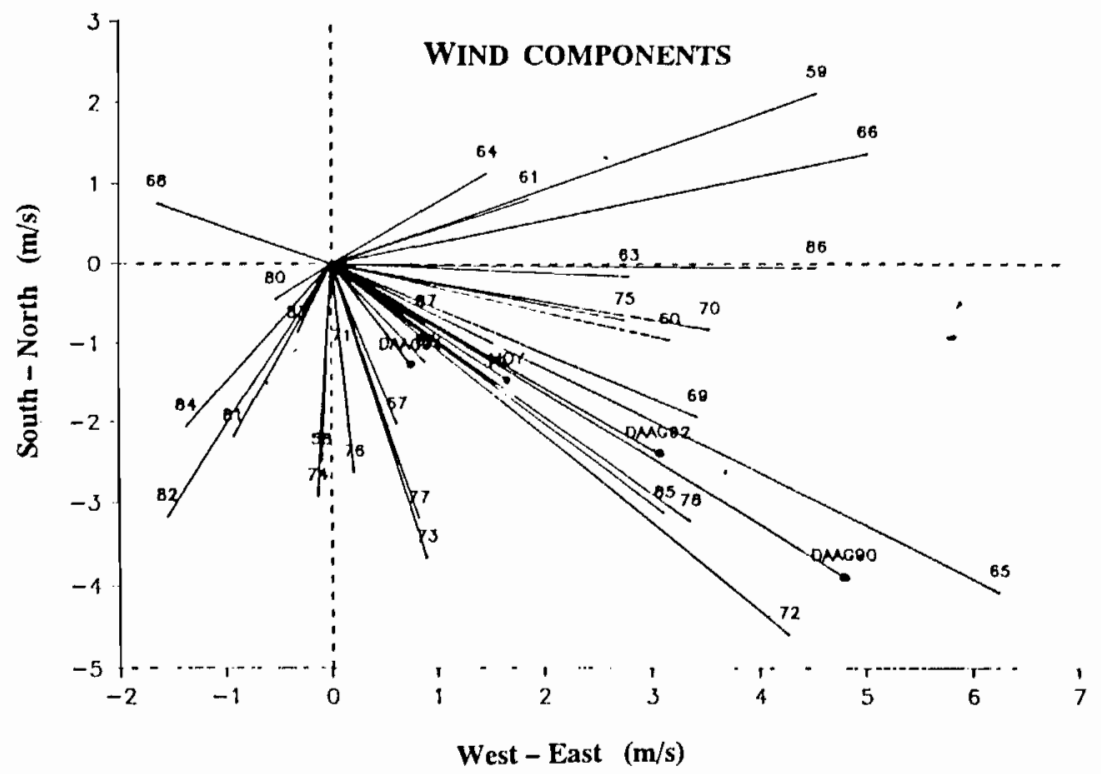

Figure 6. - Wind mean components observed at Cap Ferret (Météo France data) during the second decade of April from 1958 to 1987 and mean components observed during DAAG surveys (1990 to 1992).

from 1990 survey have high values for energy index and were detected nearshore. Evening shoals from 1991 survey have low energy index values and were detected offshore.

The patterns of the cross modal classes (shoal hour detection $X$ survey) seem similar but are in different positions on the factorial plane.

\section{DISCUSSION}

The data structure is characterized by five descriptor groups: size, external outline unevenness, water column position, internal structure degree and shape. Size and external outline unevenness are correlated groups of descriptors, but are not correlated with the water column position or with the degree of internal structure. This pattern has already be seen in results from other surveys (Scalabrin et al., 1992) and is a sign of stability in the data structure for acoustic surveys, at least in the Bay of Biscay.

Shoal sizes are at the same order of magnitude as those found by Mais (1974). Analyzing 22834 anchovy shoals detected during 1966 to 1971 in the California current, he found that shoal length varied from 5 to $385 \mathrm{~m}$, with a mean value of $29 \mathrm{~m}$ and a positively skewed distribution. Shoal lengths found here vary from 3 to $488 \mathrm{~m}$, with a mean of $23 \mathrm{~m}$ and also a highly positive skewed distribution $(98.6 \%$ of length values were smaller than $100 \mathrm{~m}$ ). The largest values may be explained by the presence of other species such as horse-mackerel which form larger shoals than anchovy (Scalabrin, 1991).

Misund (1991) studying herring, saithe and sprat shoals in the North Sea, found no significantly external shape differences among the species or length groups of a species in the various research regions. However, regional differences were found for the crosswise-to vertical proportion. He also found that the shape of shoals was independent of their size but significantly influenced by the swimming depth of the shoal, with flattened, discoid shoals towards the surface, more spherical in midwater and tendencies towards flattened bottom shoals.

Our results suggest a general trend where horizontal dimensions are significantly larger than the vertical extent. The distribution of elongation values is positively skewed with a mean value of 6 and the mode at 3 , meaning that the shape of shoals tend to be more discoid than spherical. No significant relation was found between shape and shoal swimming depth, but this result may be a consequence of the PCA method, which is a linear one.

Differences in shoal size, external outline unevenness and relative water column position are significant between bathymetric zones with stable patterns between years (fig. $4 c$ and $5 a$ ). These differences may be related to species distribution, since mackerel was found offshore (table 1).

Differences in shoal size and water column position are significant between morning, afternoon and evening shoals ( $f g .4 e$ and $5 b$ ). Afternoon shoals are closer to the bottom according to results found by Kemmerer (1980) when studying the diurnal movement and the inshore-offshore migration of Brevoortia patronus. Kemmerer relates this behaviour to variations in light intensity. But size values of morning and evening shoals are in opposition with Kemmerer's results. There has been no attempt to study diel inshore-offshore migration, because only 
data between 7 AM and 9 PM were analysed over a large amplitude bottom depth values ( 25 to $160 \mathrm{~m}$ ).

The shoal energy index 1 relates shoal intemal structure and packing density. Packing density seems to be uncorrelated with shoal size, shape, outline unevenness or water column position. These results are in accordance with general findings by Misund (1991) and Hampton (1974).

Over-all, packing density does not seem to vary considerably since the energy index factor account for $16 \%$ of the data variance, and the variation coefficient for the shoal energy index 1 is very small $(0.7)$. No packing density differences were found between surveys, meaning that temporal variability measured between years is extremely low. Mais (1974) found that within a given area and time period, shoaling densities varied only slightly.

- Differences are more significant between bathymetric zones. Nearshore shoals seem to be better structured, with higher packing density values than offshore shoals ( $f g .4 d$ ). Again differences may be related to species distribution, since sardine shoals present high values for shoal energy, index 1 and 2, (Scalabrin, 1991), and sardine is a nearshore species. The upward shift of the 1991 pattern with respect to the energy index factor ( $f g .4 d$ ) may be related to the widespread distribution of sardine biomass far from the coast in 1991 (table 1).

It was not possible to find a relationship between shoal hour detection and energy descriptors or packing density. High values of energy descriptors for 1990 afternoon shoals appeared as a consequence of the sampling trajectory and is species dependant. During the 1990 survey, afternoon transects were often nearshore in contrast to 1991 where the afternoon transects were mostly offshore.

One interesting result from this study is the significant difference in shoal size, position in the water column and bottom depth between surveys. Shoal detections from the 1991 survey are larger (by a factor of 1.5), farther from the bottom and over higher bottom depths than 1990 shoals (table 4).

The total number of shoals in both years are quite similar, but the distribution of the number of shoals between bathymetric zones is very different since only $4 \%$ of total shoal number were found nearshore in 1991 (table 3). As the number of shoals is constant, this means that an offshore shift of the biomass happened in 1991, or conversely, shoals were near to the coast in 1990 . Shoal bottom depth mean values are significantly different between years, $79 \mathrm{~m}$ in 1990 and $101 \mathrm{~m}$ in 1991 (table 4). The offshore shift of biomass concerns principally sardine and anchovy shoals (table 1).

It is difficult to explain this kind of variability in the absence of long time-series of observations and without considering other variables. Differences on relative shoal position in the water column and bottom depth mean values may be explained by the offshore shift of biomass, since intermediate zone and offshore shoals are farther from the bottom than nearshore shoals.

Differences may be species dependent. Different species composition may modify the frequency distribution of size descriptors, changing significantly mean values. Indeed, $3.1 \%$ of shoal cross sectional area (vertical surface) observations have larger values than $400 \mathrm{~m}^{2}$ for 1991 survey against $0.6 \%$ for 1990 survey. The positive mean value drift may be related to greater abundance of larger size shoaling species, such as horse-mackerel. But the drift of mode values, from $21 \mathrm{~m}^{2}$ in 1990 to $28 \mathrm{~m}^{2}$ in 1991 , could not be explained by different species composition alone.

Differences in shoaling behaviour and species distribution behaviour may also be related to weather and sea conditions. For the 1990 survey, $60 \%$ of workable days were under bad sea conditions with only $8 \%$ for 1991 survey. During both surveys, the wind came from the north-west but with highest intensity values for 1990 survey (fig. 6), which could explain a nearshore shift of biomass.

There are some models relating shoal size and behaviour to environmental conditions. Duffy and Wissel (1988) used a simple energy-balance model, relating energetic requirements of fish shoals to food production, to predict shoal sizes. Under model assumptions, food does not set a lower limit to shoal size, but maximum shoal size appears likely to be limited by mean food availability. Changes in food supply will cause changes in both shoal size and feeding behaviour.

The spring season is characterized by alternating turbulent and calm sea periods. During a turbulent period, plankton production is slowed down, to be increased during the post-turbulent calm period. Plankton production would be maximal when there is a tuning between auxiliary energy injection rhythm and biological events (Frontier and Pichod-Viale, 1991). It is possible that differences in plankton production conditions between 1990 and 1991 could change food availability and the differences in shoal size values could be explained by Duffy and Wissel's hypothesis.

Swartzman (1991) modelled the link between predation and shoaling dynamics and how shoaling is affected by predator abundance. The model suggested that shoal size and shoal numbers are sensitive to predation pressure, with shoals being larger under low predation pressure. Misund (1991) observed that the average herring shoal size was smallest where the predation was higher. This kind of behaviour was also observed during intense fishing activity. Kemmerer (1980) found that fishing sets of Brevoortia patronus were larger when caught on Monday, following little or no fishing pressure over the weekend.

It would be possible to associate turbulent sea conditions to an external pressure exercising an influence on shoal size behaviour at the same way as predation pressure. Under turbulent conditions, shoals 
would split into smaller ones increasing the number of shoals. The number of shoals in 1990 and 1991 is quite similar, but the mean shoal number per nautical mile is higher for the 1990 survey (19 shoals/nautical mile against 16 for 1991 survey). Under bad weather conditions shoals were smaller and greater in number.

Diner and Le Men (1983) observed different behaviours for shoals detected in the same region within a one week gap. Differences were probably related to changes on oceanographic conditions. The first group of shoals (numerous, small and close to the bottom) were detected under a typical winter vertical homeothermic condition. One week later, the water column was stratified with a sharp warming up of surface water, shoals were larger and farther from the bottom.

A relation may be deduced between shoal behaviour and general oceanographic conditions. Turbulence caused by strong wind usually implies that a homogeneous water layer is higher with a deeper thermocline and lower plankton production. This situation is generally followed by a calm period with the thermocline coming up closer to the surface and with higher plankton production. It is possible that global size variability of shoals could be explained by two related mechanisms: turbulence as an external physical pressure may limit formation of large shoals, since communication between the shoal center and outsider fishes must be greatly disturbed; as a consequence of turbulence, food availability diminishes strengthening the tendency to smaller shoal size.

\section{CONCLUSION}

The description of wild shoal detections made by a vertical echo-sounder was improved by the use of MOVIES-B software. Size and external outline unevenness are correlated groups of descriptors, but are not corrrelated with the water column position and internal structure degree. Shoal detections are significantly different between bathymetric zones in the same region with similar patterns in each year. This spatial variability is related to the species distribution in the bathymetric zones. It was not possible to set a relation between day-time and shoal detection description in order to verify different shoaling behaviour. Although, if it was not possible to explain size variability between years, the study shows the need of improving shoal description with more environmental variables. To study spatial or temporal variability in size and behaviour of shoals more knowledge of the productivity level and availability of food, oceanographic conditions, predator pressure and accurate identification of shoal species, is required.

\section{Acknowledgments}

We would like to thank A. Weill, B. Liorzou, N. Diner and the anonymous reviewers for their helpful comments, K. Sebedio and J. Simmonds who kindly improved English final version.

\section{REFERENCES}

Appenzeller A. R., W. C. Leggett, 1992. Bias in hydroacoustic estimates of fish abundance due to acoustic shadowing: evidence from day-night surveys of vertically migration fish. Can. J. Fish. Aquat. Sci., 49, 2179-2189.

Buerkle U., 1987. Photographic and acoustic measurements in a large aggregation of herring. In: International Symposium on Fisheries Acoustics, June 22-26, Seattle, Washington, USA.

Diner N., R. Le Men, 1983. Evaluation acoustique des stocks de poissons pélagiques dans la partie sud du Golfe de Gascogne en avril-mai 83. ICES CM. 1983/H:44.

Duffy D. C., C. Wissel, 1988. Models of fish size in relation to environmental productivity. Ecol. Model., 40, 201-211.

Elminowicz A., 1975. Measurements of sardine schools by hydroacoustic apparatus. ICES CM. 1975/B:14-27.

Frontier S., D. Pichod-Viale, 1991. Ecosystèmes: structure, fonctionnement, évolution. Masson, Paris, 392 p.
Graves J., 1977. Photographic method for measuring spacing and density within pelagic fish schools at sea. Fish. Bull. U.S., 75, 230-233.

Hampton I., J. J. Agembag, D. L. Cram, 1979. Feasibility of assessing the size of the south west african pilchard stock by combined aerial and acoustic measurements. Fish. Bull. S. Afr., 11, 10-22.

Hara I., 1985. Shape and size of japanese sardine school in the waters off the Southeastern Hokkaido on the basis of acoustic and aerial surveys. Bull. Jpn. Soc. Sci. Fish., 51, 41-46.

Johannesson K. A., G. F. Losse, 1973. Some results of observed abundance estimations obtained in several UNDP/FAO resource survey projects. In: Symp. On Acoustics Methods in Fisheries Research, FAO, cont. No. 3., 77 p.

Kemmerer A. J., 1980. Environmental preferences and behavior patterns of Gulf Menhaden (Brevoortia patronus) inferred from fishing and remotely sensed data. $I n$ : Fish 
behavior and its use in the capture and culture of fishes, J. E. Bardach et al. ed., ICLARM, Philippines, 345-370.

Laurec A., 1979. Analyse des données et modèles prévisionnels en écologie marine. Thèse $\mathrm{dr}$. Etat èsSciences Naturelles, Univ. Aix-Marseille.

Lebart L., A. Morineau, T. Lambert, 1988. SPAD.N: Système Portable pour l'Analyse des Données version 1. 2. CISIA, Sèvre, $306 \mathrm{p}$.

Lebart L., A. Morineau, K. M. Warwick, 1984. Multivariate Descriptive Statistical Analysis. John Wiley \& Sons, New York, $231 \mathrm{p}$.

Legendre L., P. Legendre, 1984. Ecologie Numérique. Masson et Presses de l'Université du Québec, Paris. Tome 1 et 2,260 et 335 p.

MacLennan D. N., E. J. Simmonds, 1992. Fisheries Acoustics. Chapman \& Hall, London, 325 p.

Mais K. F., 1974. Pelagic fish surveys in the California current. Fish. Bull. U.S., 162, 79 p.

Massé J., 1988. Utilisation de l'écho-intégration en recherche halieutique. Rapp. IFREMER, DRV-88. 030RH, Nantes.

Misund O. A., 1991. Swimming behaviour of schools related to fish capture and acoustic abundance estimation. Ph. D. Thesis, Dep. fish. mar. biol., Univ. Bergen, Norway.

Misund O. A., A. Aglen, 1992. Swimming behaviour of fish schools in the North Sea during acoustic surveying and pelagic trawl sampling, ICES J. Mar. Sci., 49, 325-334.

Misund O. A., A. Aglen, A. K. Beltestad, J. Dalen, 1992. Relationships between geometric dimensions and biomass of schools. ICES J. Mar. Sci., 49, 305-315.

Partridge B. L., 1981. Internal Dynamics and interrelations of fish in schools. J. Comp. Physiol. 144, 313-325.
Pitcher T. J., B. L. Partridge, 1979. Fish school density and volume. Mar. Biol, , 54, 383-394.

Scalabrin C., 1991. Recherche d'une méthodologie pour la classification et l'identification automatiques des détections acoustiques des bancs de poissons. Rapp. IFREMER, DITINPA 91.23.

Scalabrin C., A. Weill, N. Diner, 1992. The structure of multidimensional data from acoustic detection of fish shools. In: European conference on underwater acoustics, ed. M. Weydert, Elsevier Applied Science, 141-146.

Shaw E., 1978. Schooling fishes. Am. Sci., 1978, 66, 166-175.

Van Olst J. C., J. R. Hunter, 1970. Some aspects of the organization of fish scools. J. Fish. Res. Board Can., 27, 1225-1238.

Smith P. E., 1970. The horizontal dimensions and abundance of fish schools in the upper mixed layer as measured by sonar. In: Proc. Int. Symp. On Biological Sound Scattering in the Ocean, ed. G. B. Farquhar, Washington D. C., Department of the Navy, 563-591.

Squire J. L., 1978. Northern anchovy school shapes as related to problems in shool size estimation. Fish. Bull. U.S., 76, 443-448.

Swartzman G., 1991. Fish school formation and maintenance: a random encounter model. Ecol. Model., 56, 63-80.

Weill A., C. Scalabrin, N. Diner, 1993. MOVIES-B: an acoustic detection description software. Application to shoal species classification. Aquat. Living Resour., 6, 255-267.

Whitney R. R., 1969. Schooling of fishes relative to available light. Trans. Am. Fish. Soc., 98, 497-504. 